Trauma Surgery \& Acute Care Open

ORIGINAL ARTICLE

\title{
Creation of the first Hartford Consensus compliant elementary school in the USA
}

\author{
Elie Ramly, Jordan D Bohnen, Peter Fagenholz, Dante Yeh, George Velmahos, \\ Marc DeMoya, Haytham Kaafarani, Katheryn Butler, Jarone Lee, David R King
}

Division of Trauma, Emergency Surgery, and Surgical Critical Care, Harvard Medical School, Massachusetts General Hospital, Boston,

Massachusetts, USA

Correspondence to Dr David R King;

Dking3@mgh.harvard.edu

This was presented at the 29th Annual Assembly of the Eastern Association for the Surgery of Trauma.

Received 18 July 2016 Revised 30 August 2016 Accepted 5 September 2016
To cite: Ramly $\mathrm{E}$, Bohnen JD, Fagenholz $P$, et al. Trauma Surg Acute Care Open Published Online First: [please include Day Month Year] doi:10.1136/ tsaco-2016-000031

\section{ABSTRACT}

Background The Hartford Consensus established a framework for minimizing deaths due to mass shootings, specifically eliminating preventable deaths due to limb exsanguination. Two major principles defined within this framework are (1) redefining the first responder role and (2) the ubiquitous availability of proper training in application of hemorrhage control techniques, including tourniquets. We hypothesized that this hemorrhage control posture could be fully translated into an elementary school.

Methods Following institutional review board approval, all teachers at a prekindergarten through 8th grade elementary school underwent short, intensive instruction on their role as a first responder, as well as indications and proper technique for hemorrhage control and tourniquet application for limb exsanguination. All teachers self-reported their confidence in their role as a first responder as well as tourniquet application indications and technique before and after instruction. Following instruction, teachers were evaluated on proper tourniquet application technique on a simulated limb to assess competence.

Results 26 elementary school teachers and 2 administrative staff underwent training. All reported low confidence in their role as a first responder and in tourniquet application indication and technique before training. Following training, all teachers reported high confidence. Testing demonstrated all teachers were competent in the tourniquet application technique. Following training, each classroom was equipped with a purpose-made commercial tourniquet, and a dedicated hemorrhage control bag was placed in the school's central administrative office.

Conclusions All teachers were successfully trained to act as first responders and in correct hemorrhage control techniques, which was verified by testing. This is the first elementary school to universally adopt a hemorrhage control posture to eliminate preventable deaths from limb exsanguination advocated by the Hartford Consensus.

\section{INTRODUCTION}

The Hartford Consensus advocates a variety of approaches to minimize deaths following active shooter events. Adoption of the THREAT framework ( $\mathrm{T}$-threat suppression, $\mathrm{H}$-hemorrhage control, RE-rapid extrication to safety, A-assessment by medical providers, and $\mathrm{T}$-transport to definitive care) and an aggressive hemorrhage control posture are central to improving survivability. ${ }^{1-4}$ One major principle advocated by the
Hartford Consensus is that no one should die from preventable limb exsanguination. Prevention of death from limb exsanguination requires a redefinition of the role of first responder, as well as ubiquitous training in limb hemorrhage control techniques. Finally, hemorrhage control devices, such as tourniquets, must be made widely available.

Many mass shooting and other mass casualty events create circumstances where immediate care of injured casualties may not be possible. The scene may be locked down in order to control the dangerous environment and allow law enforcement to eliminate the threat. This may introduce a delay in casualty treatment by professional medical responders. ${ }^{5}$ The Hartford Consensus advocates for redefining the role of first responder to those already on the scene of these events-that is, adopting a philosophy of immediate self-aid and buddy-aid, where the victims immediately become the first responders. Under these dire circumstances, the injured and uninjured victims can facilitate limb hemorrhage control for the injured or for themselves, but this requires adoption of the first responder role, proper hemorrhage control training, and ubiquitous availability of tourniquets. Additionally, this psychomotor skill set cannot be limited only to school medical personnel (such as the school's nurse), but instead this skill set should be universally adopted by all teachers. We hypothesized that this aggressive hemorrhage control posture could be fully translated to an elementary school.

\section{METHODS}

Following institutional review board approval, school district approval, and individual informed consent from each teacher, a prekindergarten through eighth grade elementary school was selected for intervention. A unique, civilian, nongraphic training program was developed that would heavily focus on psychomotor skill development, leveraging other existing military and civilian prehospital hemorrhage control educational techniques. Between January and May 2015, teachers and administrative staff underwent $\sim 1$ hour of intensive education and training in two equally divided groups (grouping of teachers for training was for convenience and not for comparison). Training was conducted by a physician expert who emphasized three major goals: (1) advocating for teachers to assume the role of first responder in active shooter events within the THREAT framework, (2) understanding the principles of limb 
hemorrhage control and indications for tourniquet application, and (3) instruction on proper tourniquet application technique. The two major bleeding control cognitive end points were to understand bleeding control escalation, to understand that limb inflow much be occluded to achieve hemostasis with a tourniquet. A three-step incremental, escalating approach to hemorrhage control was taught: (1) apply strong, deliberate, direct pressure with wound packing if the wound geometry permits packing; (2) if direct pressure and wound packing fails, apply a tourniquet; (3) if still bleeding with tourniquet in place, ensure the tourniquet is applied properly, apply a second tourniquet adjacent to the first (if a second tourniquet is available), and apply additional direct pressure on the wound. No teaching aids were used except the mannequin thigh and a white dry-erase marker board, which was used to draw diagrams to answer questions.

Tourniquet application education by practical exercise was completed on an improvised thigh mannequin using the Combat Application Tourniquet, Generation 6 (Composite Resources, North Carolina, USA). Following instruction, teachers practiced on the thigh mannequin, with instructor feedback, until they self-reported comfort and competence in the procedure. Individual teachers were then observed applying the tourniquet to the mannequin limb. Objective competence in the procedure was considered achieved when each teacher successfully and correctly applied the tourniquet in three consecutive repetitions. If an error was detected in application, teachers were given immediate feedback and attempted another application without guidance. This process continued until three successful applications were completed serially without instructor feedback or corrections. The key steps required to be considered competent were (1) proper routing of the free end of the tourniquet through the buckle; (2) adequate pretensioning of the tourniquet; and (3) proper twisting and securing of the windlass.

Teachers self-reported confidence as a first responder and in their ability to apply hemorrhage control techniques, before and after training using a Likert scale survey instrument. Categorical responses were used to rate the statements "I have confidence I can assume the role of first responder during an active shooter or mass casualty event" and "I have confidence I can properly apply a tourniquet to a massively bleeding limb during an active shooter or mass casualty event". The five-point Likert scale options were (1) strongly disagree, (2) disagree, (3) unsure, (4) agree, and (5) strongly agree. Results were compared using the Wilcoxon rank-sum test.

Basic demographic information was collected, as was total classroom time and each individual teacher's time to competence during the practical exercise.

\section{RESULTS}

In total, 26 teachers and 2 teacher-administrative personnel underwent training, representing the entire professional staff at the elementary school. The age of the teachers ranged from 22 to 62 years old. There were four men, and the balance of the teachers were women. The only formal medical training previously received was basic cardiopulmonary resuscitation, reported by 19 of the teachers.

Before training, all teachers reported no or low confidence in their ability to act as a first responder, answering 'strongly disagree' or 'disagree', as well as universally indicating no confidence, answering 'strongly disagree' with regard to confidence in the tourniquet application procedure. Total didactic instruction time in each session was $45 \mathrm{~min}$ for group 1 and $53 \mathrm{~min}$ for group 2. Total practical time to achieve self-reported competence was a mean of $12 \pm 5 \mathrm{~min}$. Following self-reported competence, 18 of 28 teachers successfully completed three serially observed correct repetitions and were considered competent. Ten teachers required between one and three corrections with feedback before completing three successful serial applications without guidance. All teachers completed the entire training in $<1.5$ hours. Following instruction, all 28 reported high confidence (answering 'agree' or 'strongly agree') in their ability to act as a first responder and to correctly complete tourniquet application during an active shooter event. This represents a significant improvement in confidence with respect to both questions $(\mathrm{p}<0.05)$.

Following training, a tourniquet was donated to each teacher placed in their classroom. A centralized hemorrhage control bag containing gloves, topical hemostatic gauze, standard gauze, and multiple tourniquets was also donated and placed in a dedicated cabinet (figure 1) next to the school's automated external defibrillator (AED). This was facilitated by local philanthropy.

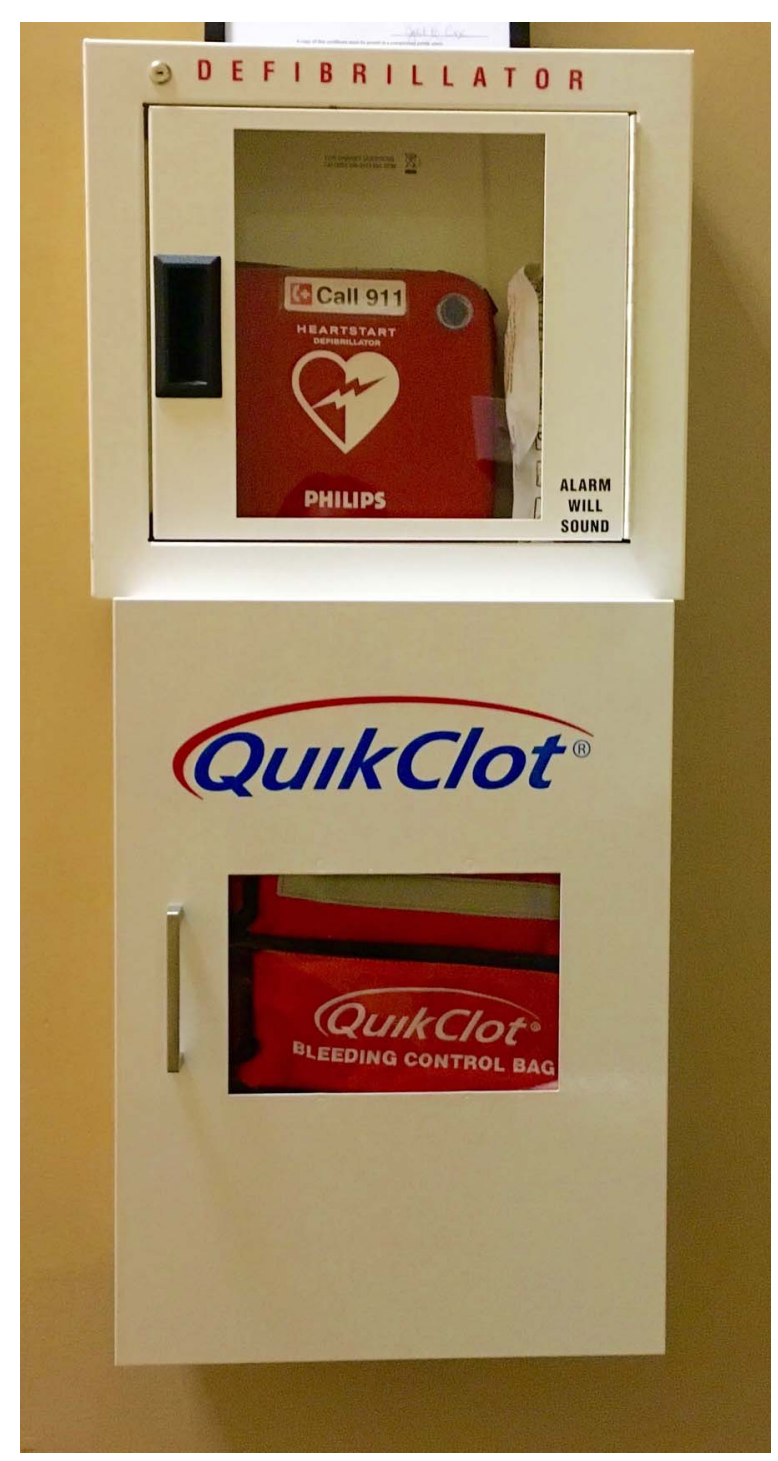

Figure 1 Hemorrhage control bag containing multiple tourniquets and rolls of wound packing co-located with an AED in the elementary school. AED, automated external defibrillator. 


\section{DISCUSSION}

Adoption of an aggressive limb hemorrhage control posture that complies with the recommendations of the Hartford Consensus is possible in an elementary school. Through a local, grass-roots program, an entire elementary school underwent training to understand the THREAT framework and to understand the necessity to adopt the first responder role. Additionally, all teachers successfully adopted a set of hemorrhage control psychomotor skills necessary to properly apply a tourniquet to stop limb exsanguination. Confidence in this new role and in the psychomotor skill set improved dramatically with a simple educational intervention. This effort, to the best of our knowledge, represents the first elementary school in the USA to adopt a hemorrhage control posture consistent with the recommendations of the Hartford Consensus. The total time investment to achieve this goal for the entire school was $\sim 3$ hours. We hope this can serve as a model training program for other elementary schools.

Training of elementary school teachers requires a different approach than training of medical professionals. This educational program was intentionally designed without graphic photos or language in order to minimize the psychological stress of this type of training. Following training, feedback was solicited from the teachers and they agreed that the knowledge and psychomotor skills could be acquired without need for graphic photos or language. All teachers generally reported a feeling of empowerment from the training program. An obvious limitation of this training is whether the acquisition of the new skill set and feeling of empowerment will translate into actionable bleeding control in a real-life mass casualty event. Additional work is being conducted to understand the rate of psychomotor knowledge decay over time with hopes of understanding how often re-training will be necessary.

Through the Joint Committee to Create a National Policy to Enhance Survivability From Mass Casualty Shooting Events, made up of representatives from the American College of Surgeons, the Federal Bureau of Investigation, the Major Cities Chiefs Association, the International Association of Fire Chiefs, the Committee on Tactical Combat Casualty Care, and the Hartford Consensus, bleeding control recommendations were recently adopted by the Department of Homeland Security within their 'Stop the Bleed' campaign. ${ }^{6}$ This campaign was then publically endorsed by President Obama. ${ }^{7}$ This endorsement, however, did not come with any legislative mandate to create a budget to educate or equip public or private organizations with training and hardware necessary to act on those recommendations. Local educational campaigns, like the one described, will be necessary to improve our national survivability to mass shooter and mass casualty events.

The necessity of this training is apparent. Critical analysis of mass shooter and mass casualty events highlights the importance of a strong hemorrhage control posture, ${ }^{8}$ especially as it relates to educational institutions. ${ }^{9}$ Formal training programs are abundant in the military ${ }^{10}$ and within the professional non-military, first responder medical community, ${ }^{11}$ however efforts to push this posture to non-medical professionals, in order to maintain the continuum of prehospital trauma care, is lacking. Educational campaigns directed at non-medical professionals within a hospital have been successful, ${ }^{12}$ however this approach has never been pushed widely to an entire elementary school.
A commonly cited goal often cited when discussing prehospital hemorrhage control is to preposition and co-locate hemorrhage control devices with a public AED. ${ }^{1}$ This goal was achieved with this current effort (figure 1).

\section{CONCLUSIONS}

Adoption of an aggressive limb hemorrhage control posture is possible in an elementary school. Teachers can rapidly acquire the knowledge and psychomotor skills necessary to adopt the THREAT framework and apply a tourniquet to prevent limb exsanguination. Public access to limb hemorrhage control needs to become a priority. It is no longer enough to 'see something, say something'. Rather, we must now teach our teachers to 'see something, do something'.

Contributors ER and JDB collected all data and wrote the first draft of the manuscript; PF, DY, GV, MD, HK, KB and JL all participated in education, data analysis, manuscript editing and revisions; DRK conceived of the study and supervised all aspects, including education, data analysis, manuscript writing, and revisions.

Competing interests None declared.

Patient consent Obtained.

Ethics approval Massachusetts General Hospital Institutional Review Board.

Provenance and peer review Not commissioned; externally peer reviewed.

Open Access This is an Open Access article distributed in accordance with the Creative Commons Attribution Non Commercial (CC BY-NC 4.0) license, which permits others to distribute, remix, adapt, build upon this work non-commercially, and license their derivative works on different terms, provided the original work is properly cited and the use is non-commercial. See: http://creativecommons.org/ licenses/by-nc/4.0/

\section{REFERENCES}

1 Jacobs LM, Joint Committee to Create a National Policy to Enhance Survivability from Intentional Mass-Casualty and Active Shooter Events. The Hartford Consensus III: implementation of bleeding control: if you see something do something. Bull Am Coll Surg 2015;100(1 Suppl):40-6.

2 Jacobs LM. Implementation of the Hartford Consensus initiative to increase survival from active shooter and intentional mass casualty events and to enhance the resilience of citizens. Bull Am Coll Surg 2015;100(1 Suppl):83-6.

3 Jacobs LM, Sinclair J, Rotondo M, Burns K, McSwain N, Brinstield K, Wade DS, Carmona R, Fabbri WP, Serino R, et al., Joint Committee to Create a National Policy to Enhance Survivability from Mass Casualty Shooting Events. Active shooter and international mass-casualty events: the Hartford Consensus II. Bull Am Coll Surg 2015;100(1 Suppl):35-9.

4 Jacobs LM, Eastman A, Mcswain N, Butler FK, Rotondo M, Sinclair J, Wade DS, Fabbri WR, Joint Committee to Create a National Policy to Enhance Survivability from Mass Casualty Shooting Events. Improving survival from active shooter events: the Hartford Consensus. Bull Am Coll Surg 2015;100(1 Suppl):32-4.

5 Jacobs LM, Burns KJ, McSwain N, Carver W. Initial management of mass-casualty incidents due to firearms: improving survival. Bull Am Coll Surg 2015;100(1 Suppl): 28-31.

6 Stop The Bleed. Nov 20, 2015. http://www.dhs.gov/stopthebleed

7 Jacobs LM Jr. The presidential directive. Bull Am Coll Surg 2015;100(1 Suppl):88.

8 King DR, Butler F, Kragh JF. Re: Tourniquet use at the Boston Marathon bombing. J Trauma Acute Care Surg 2015;79:702-3.

9 Downs S. Active shooter in educational facility. J Emerg Manag 2015;13:303-26.

10 Bennett BL, Littlejohn LF, Kheirabadi BS, Butler FK, Kotwal RS, Dubick MA, Bailey JA. Management of external hemorrhage in tactical combat casualty care: chitosan-based hemostatic gauze dressings-TCCC guidelines-change 13-05. I Spec Oper Med 2014;14:40-57.

11 Callaway DW, Smith R, Shapiro G, McKay S. Committee for Tactical Emergency Casualty Care (C-TECC) update: summer 2014. J Spec Oper Med 2014;14:134-9.

12 Jacobs LM, Burns KJ. Tourniquet application training for individuals with and without a medical background in a hospital setting. J Trauma Acute Care Surg 2015;78:442-5 